\title{
CSIR - NLC Mobile LIDAR for Atmospheric Remote Sensing
}

\author{
Sivakumar Venkataraman \\ Council for Scientific and Industrial Research, \\ National Laser Centre, Pretoria \\ University of Pretoria, Department of Geography \\ Geoinformatics and Meterology, Pretoria \\ University of Kwa-Zulu Natal, Department of Physics, Durban \\ South Africa
}

\section{Introduction}

Remote sensing is a technique for measuring, observing, or monitoring a process or object without physically touching the object under observation. The remote sensing instrumentation is not in contact with the object being observed, remote sensing allows - to measure a process without causing disturbance - to probe large volumes economically and rapidly, such as providing global measurements of aerosols, air pollution, agriculture, environmental impacts, solar and terrestrial systems, ocean surface roughness and largescale geographic features. The modern atmosphere remote sensing technique offers to study in detail, the atmospheric physics/chemistry and meteorology. In general, observation, validation, and theoretical simulation are highly integrated components of atmospheric remote sensing. Active and passive remote-sensing techniques and theories/formulation methods for measuring atmospheric and environmental parameters have advanced rapidly in recent years. Active remote sensing instrumentation includes an energy source on which the measurement is based. In this case, the observer can control the energy source and the examples of this class are RADAR, LIDAR, SODAR, SONAR etc. Passive remote sensors do not include the energy source on which the measurement is based. They rely on an external light, which is beyond the control of the observer and examples of this class are optical and radio telescopes, radiometers, photometers, spectrometers etc.

\section{LIDAR as a remote sensing probe}

LIDAR (LIght Detection And Ranging) is also called as "Optical RADAR" or "Laser RADAR". It is a powerful and versatile remote sensing technique for high resolution atmospheric studies. It complements the conventional RADAR for atmospheric studies by being able to probe the region not accessible to the RADAR and study micro-scales of the atmosphere. The LIDAR probing of the atmosphere started in early 1960s and pursued intensively over the past five decades. Fiocco and Smullins (1963) used Ruby Laser with a feeble energy of 0.5J, obtained Rayleigh scattering signals from the atmosphere upto $50 \mathrm{~km}$ altitude and also detected dust layers in the atmosphere. Ligda in 1963 made the LIDAR 
measurements of cloud heights in the troposphere. Recent developments leading to the availability of more powerful, relatively rugged and highly efficient solid state lasers and improvements in detector technology as well as data acquisition techniques have resulted, LIDARs as a potential tool for atmospheric studies. Both continuous wave and pulsed laser systems have been extensively used and they are currently operational for the study of atmospheric structure and dynamics, trace constituents, aerosols, clouds as well as boundary layer and other meteorological phenomena. Currently laser systems are being used for probing the atmosphere begin from surface (near boundary layer) to lower thermosphere altitudes (upto $100 \mathrm{~km}$ ).

\subsection{LIDAR principle}

LIDAR is one of the most powerful remote sensing techniques to probe the earth's middle atmosphere. The basic principle of probing the atmosphere by LIDAR is similar to that of the RADAR. In the simplest form, LIDAR employs a laser as a source of pulsed energy of useful magnitude and suitably short duration. Typically Q-switched ruby (wavelength=0.69 $\mu \mathrm{m}$ ) or Neodymium (wavelength $1.06 \mu \mathrm{m}$ ) laser systems are used to generate pulses having peak powers measured in tens of megawatts in the duration of 10-20 nsec. Pulses with such energy (i.e. of the order 1 joule) are directed in beams by suitable optical systems. The advantage of laser, as it has specific properties of virtually monochromatic and highly coherent and collimated.

As the transmitted laser energy passes through the atmosphere, the gas molecules and particles or droplets cause scattering. A small fraction of this energy is backscattered in the direction of the LIDAR system and is available for detection. The scattering of energy in directions other than the direction of propagation, or absorption by the gases and particles, reduces the intensity of the beam, which is said to be attenuated. Such attenuation applies to both the paths (to and fro) of the distant backscattering region.

The LIDAR backscattered energy is collected in a suitable receiver by means of reflective optics and transferred to a photo-detector (commonly referred to a photo-multiplier). This produces an electrical signal, the intensity of which at any instant is proportional to the received LIDAR signal power. Since the light travels at a known velocity, the range of the scattering region produces the signal received at any instant can be uniquely determined from the time interval of the sampled signal from the transmitted pulse. The magnitude of the received signal is determined by the backscattering properties of the atmosphere at successive ranges and by the two-way atmospheric attenuation. Atmospheric backscattering intern depends upon the wavelength of the laser energy used, and the number, size, shape and refractive properties of the particles (droplets and molecules) intercepting the incident energy. Backscattering from an assemblage of scatterers is a complicated phenomenon; in general, the backscattering increases with increasing scatterer concentrations.

The electrical signal from the photo detector thus contains information on the presence, range and concentration of atmospheric scatterers. Various forms of presenting and analyzing such signals are available. In the simplest form they may be presented on an oscilloscope in a coordinate system showing received signal intensity as a function of range. Since such signals are transient, ( $1 \mathrm{~km}$ of range is represented by an interval of time of $\sim 7 \mu \mathrm{s})$, it is necessary to photograph several such oscilloscope displays to obtain adequate data for presentation. 
Figure 1 shows the schematic diagram of LIDAR probing of the atmosphere in which $\mathrm{P}_{0}$ represents the laser-transmitted pulse energy. Let us consider at an altitude $\mathrm{z}$ the scattering take place, hence a factor $\mathrm{T}$ attenuates the intensity of light pulse. The radiation scattered in backward is $P_{0} \mathrm{~T} \beta$, where $\beta$ is the backscattering coefficient (sum of Rayleigh scattering by air molecules and Mie scattering by aerosol particles). Since the backscattered radiation travels the same distance $r$ before being detected by the telescope, it further undergoes attenuation by the same factor $\mathrm{T}$. Thus the intensity of the backscattered signal detected at the telescope becomes $\frac{P_{0} T^{2} \beta A}{r^{2}}$, where $\mathrm{A}$ is the area of the telescope receiving the backscattered radiation.

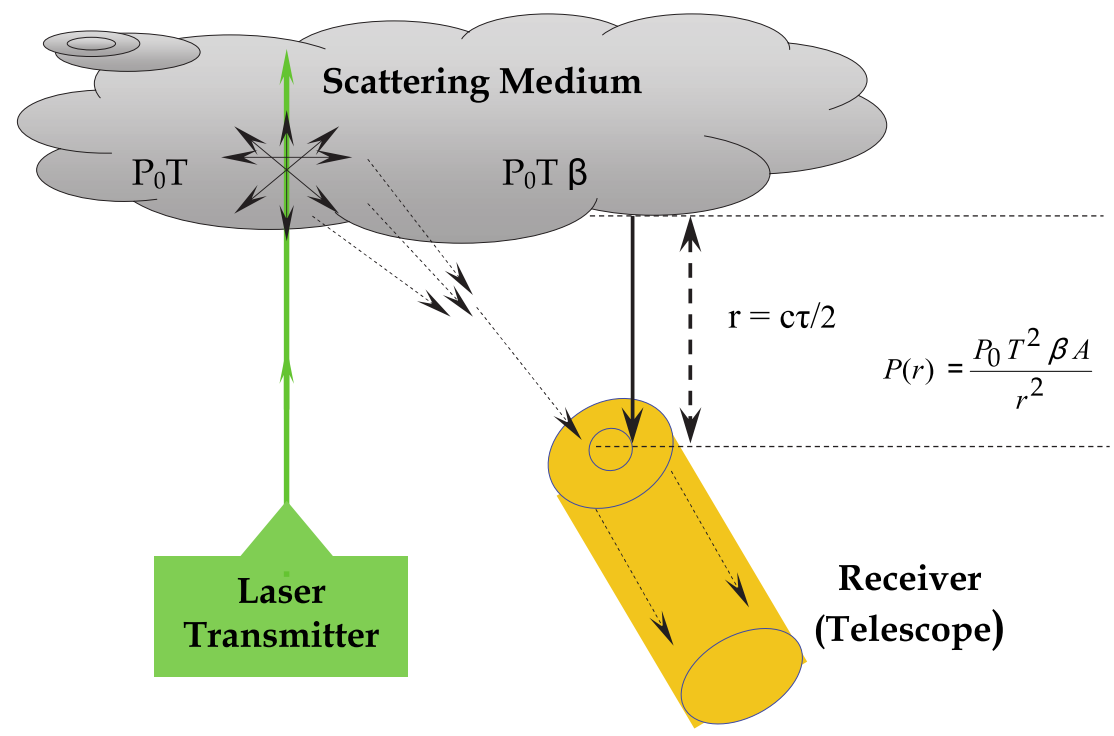

Fig. 1. Schematic diagram showing the basic principle involved in LIDAR probing of the atmosphere.

LIDARs may be configured into two ways; (a) Mono-static configuration in which both transmitter and receiver are collocated. (b) Bi-static configuration in which both transmitter and receiver are separated by some distance.

\subsection{LIDAR equation}

The transmitted laser beam gets scattered in all directions at all altitudes, the backscattered echoes are received by the telescope and their intensities are measured. The field of view of the telescope is kept larger than beam divergence, in order to accommodate the beam completely at all altitudes. The received signal intensity is described in terms of the LIDAR equation as given by (Fiocco, 1984);

$$
P(r)=P_{0} \eta\left(\frac{A}{r^{2}}\right)\left(\frac{c \tau}{2}\right) \beta(r) \exp \left[-2 \int \alpha(r) d r\right]
$$


Where $\mathrm{P}(\mathrm{r})$ is the instantaneous power received at time $\mathrm{t}$ from an altitude (range) $r, \mathrm{P}_{0}$ is the transmitted power, $\eta$ is the system constant which depends on the transmitter and receiver efficiencies. A is the area of primary (collecting) mirror of the receiving telescope. The term $\left(\frac{A}{r^{2}}\right)$ is the solid angle subtended by the primary mirror at the range $r$. This simple expression for solid angle is applicable for monostatic only because all the transmitted energy contributes to the backscattered signal from the range r. The term $\left(\frac{c \tau}{2}\right)$ gives the length of the illuminated path, which contributes to the received power, where $c$ is the velocity of light and $\tau$ is the pulse duration of the laser beam.

The $\left(\frac{c \tau}{2}\right)$ term determines the minimum spatial resolution available in the direction of the beam propagation. In the transverse direction the spatial resolution depends on the laser beam width at particular altitude. In a typical LIDAR system the pulse duration of the laser beam is of the order of few nanoseconds and the beam divergence is less than a milli-radian, which corresponds to a scattering volume of a few cubic meters. This is the greatest advantage of the LIDAR technique which is not possible by any other atmospheric remote sensing technique.

$\beta(r)$ is the volume backscattering coefficient of the atmosphere at range $\mathrm{r}$. It gives the fractional amount of the incident energy scattered per steradian in the backward direction per unit atmospheric path length and has the dimension of $\mathrm{m}^{-1} \mathrm{sr}^{-1} \cdot \alpha$ is the volume attenuation coefficient of the atmosphere and has the unit of $\mathrm{m}^{-1}$, defined as twice the integral between the transmitter and the scattering volume to obtain the net transmission.

The term $\alpha$ and $\beta$ include the contribution from air molecules, aerosols and the other atmospheric species. The problem related with the LIDAR equation is that it contains two unknowns, $\alpha$ and $\beta$, which make it difficult to obtain the general solution. Appropriate inversion methods (Fernald et al., 1984; Klett, 1981 \& 1985) have been developed to solve the equation. The LIDAR equation however assumes only single scattering. Contribution arising from multiple scattering is important for high turbidity cases such as clouds and fogs.

\subsection{LIDAR scattering / absorption mechanisms}

As the radiant energy passes through the atmosphere it undergoes transformations like absorption and scattering. Absorption (or emission) of radiation takes place when the atoms or molecules undergo transition from a energy state to another. Scattering is the deflection of incoming solar radiation in all directions. Scattering of radiation depends to a large extent on particle size. There are several scattering / absorption mechanisms that occur when the laser energy interacts with the atmosphere. The predominant scattering is quasi-elastic scattering from aerosols (Mie scattering) or molecules (Rayleigh Scattering). The quasi-elastic nature arises from the motion of the molecules or aerosols along the direction of the laser beam. Aerosols, generally move with the air mass, give rise to smaller Doppler shifts, while the molecules, move at high speed, give rise to larger Doppler shifts. Another form of atmospheric elastic scattering is resonance fluorescence. In-elastic scattering includes Raman Scattering and Non-Resonance Fluorescence. These 
scattering processes, sometimes in combination with molecular absorption, form the basis for various types of LIDAR remote sensing techniques. The most well known is DIAL (DIfferential Absorption LIDAR) or DASE (Differential Absorption Scattering Energy). Table 1 summarizes these mechanisms.

\begin{tabular}{|l|l|}
\hline \multicolumn{1}{|c|}{ Technique } & \multicolumn{1}{c|}{ Atmospheric measurements } \\
\hline Rayleigh Scattering & Air Density and temperature (above $35 \mathrm{~km}$ ) \\
\hline Mie Scattering & Cloud, Smog, Dust, Aerosols (Below $35 \mathrm{~km}$ ) \\
\hline Raman Scattering & $\begin{array}{l}\mathrm{N}_{2}, \mathrm{CO}_{2}, \mathrm{H}_{2} \mathrm{O} \text { and Lower Atmosphere temperature } \\
\text { (less than } 20 \mathrm{~km})\end{array}$ \\
\hline $\begin{array}{l}\text { Differential Absorption } \\
\text { LIDAR (DIAL) }\end{array}$ & $\begin{array}{l}\text { Trace Species, like } \mathrm{O}_{3}, \mathrm{NO}_{2}, \mathrm{CO}_{2}, \mathrm{CH}_{4}, \mathrm{CO}, \mathrm{H}_{2} \mathrm{O} \\
\text { (for upto } 50 \mathrm{~km})\end{array}$ \\
\hline
\end{tabular}

Table 1. Main scattering / absorption process of laser-atmosphere Interactions.

\subsubsection{LIDAR scattering / absorption mechanisms}

\section{Rayleigh scattering}

In 1890's Lord Rayleigh showed that the scattering of light by air molecules is responsible for the blue color of the sky. He showed that, when the size of the scatterer is small compared to the wavelength of the incident radiation. Rayleigh scattering mainly consists of scattering from the atmospheric gases. This type of scattering is varies nearly as the inverse of fourth power of interactive wavelength and directly proportional to sixth power of the radius of the scatter.

\section{Mie scattering}

When the sizes of the scattering particles are comparable to or larger than the LIDAR wavelength, the scattering is governed by Mie theory. Pollen, dust, smoke, water droplets, and other particles in the lower portion of the atmosphere cause Mie scattering. Mie scattering is responsible for the white appearance of the clouds. Note that for a given incident wavelength as the size of the scatterer is reduced, the scattering computed using Mie theory coincides with the results obtained using Rayleigh formula. Thus Rayleigh scattering is said to be a special case of Mie scattering. The Mie scattering is directly proportional to wavelength and proportional to the volume of the scatterers.

\section{Raman scattering}

Raman scattering is the process involving an exchange of a significant amount of energy between the scattered photon and the scattering species. Thus the Raman scattering component is shifted from the incident wave frequency by an amount corresponding to the internal energy of the species. The Raman scatter has both down-shifted (stokes) and upshifted (anti-stokes) lines in its spectrum. The cross section for Raman scattering is small and compared to Rayleigh scattering, it is smaller by about three orders of magnitude. However, by LIDAR technique, it offers a valuable means for identifying and monitoring atmospheric constituents and also for temperature measurements in the lower atmosphere. The technique makes use of stokes line since its intensity is much greater than that of anti-stokes line. 


\section{Differential absorption technique}

The most sensitive and effective absorption method for the measurement and monitoring of air pollutants is the "Differential Absorption LIDAR (DIAL)" technique. In this technique, the pulsed laser transmitter emits signals at two wavelengths, $\lambda_{\text {on }}$ and $\lambda_{\text {off }}$ corresponds to absorption line and other outside the absorption line. The received backscatter power on and off wavelength is given by

$$
\begin{gathered}
P_{o n}=\frac{E_{o n} \beta_{o n}(r) C}{2 r^{2}} \exp \left[-\int_{0}^{r} 2 \alpha_{o n}\left(r^{\prime}\right) d r^{\prime}\right] \\
P_{o f f}=\frac{E_{o f f} \beta_{o f f}(r) C}{2 r^{2}} \exp \left[-\int_{0}^{r} 2 \alpha_{o f f}\left(r^{\prime}\right) d r^{\prime}\right]
\end{gathered}
$$

Where $\mathrm{P}$ is the received backscatter power at time $\mathrm{t}=2 \mathrm{r} / \mathrm{c}, \mathrm{r}$ is range, $\mathrm{E}$ is the transmitted laser pulse energy, $\beta$ is the atmospheric backscatter coefficient, $\alpha$ is the atmospheric extinction coefficient and $C$ is system constant. The atmospheric absorption and extinction coefficient can be expressed interms of aerosol and molecular components.

In this method, the ratio of the received backscattered power between $\lambda_{\text {on }}$ and $\lambda_{\text {off }}$ wavelength is directly proportional to the number concentrations of the molecule/gaseous pollutants.

Table-2 provides the primary laser sources, which are used for atmospheric applications. In which solid-state lasers are popular. The first laser systems used with the flash lamp pumped is a Q-switched ruby laser. Now it has been implemented in Nd-YAG laser system also.

\begin{tabular}{|l|l|l|l|}
\hline \multicolumn{1}{|c|}{ Laser } & \multicolumn{1}{|c|}{ Wavelength } & \multicolumn{1}{|c|}{ Energy per pulse } & \multicolumn{1}{|c|}{$\begin{array}{c}\text { Efficiency } \\
\text { (\%) }\end{array}$} \\
\hline Ruby & $0.694 \mu \mathrm{m}$ & 2-3 J at $0.5 \mathrm{~Hz}$ & $0.1-0.2$ \\
\hline $\mathrm{Nd}: Y A G$ & $1.06 \mu \mathrm{m}$ & $1 \mathrm{~J}$ at $10 \mathrm{~Hz}, 10 \mathrm{~ns}$ pulse & $1-2^{*}$ \\
\hline $\mathrm{CO}_{2}$ & $9-11 \mu \mathrm{m}$ multi-line & $1-10 \mathrm{~J}$ at $1-50 \mathrm{~Hz}$ & $10-30$ \\
\hline $\mathrm{CO}_{2}$ & Tunable & 0.1 J at $10 \mathrm{~Hz}$ & 5 \\
\hline $\mathrm{CO}$ & $5-6.5 \mu \mathrm{m}$ & $\begin{array}{l}\text { Not very popular for pulsed } \\
\text { operation }\end{array}$ & 10 \\
\hline $\begin{array}{l}\text { Dye lasers Flash } \\
\text { lamp pumped }\end{array}$ & $0.35-1.0 \mu \mathrm{m}$ & $0.1-20 \mathrm{~J}$ & 1 \\
\hline
\end{tabular}

*Note: More recently using diode array pumping more than $20 \%$ efficiencies have been achieved.

Table 2. Primary laser sources used for atmospheric applications

\subsection{Applications of LIDAR}

LIDARs are used in variety of applications in the field of atmospheric science. Some of the main applications are outlined, below. 


\section{LIDAR for the aerosol studies}

The LIDAR provides measurements of the optical backscattering cross section of air as a function of range and wavelength. This information may be subsequently interpreted to obtain profiles of the aerosol concentration, size distribution, refractive index, scattering, absorption and extinction cross sections and shape. The scattering involves with aerosol is mainly due to Mie scattering. Details on Mie scattering are provided in the earlier section.

\section{LIDAR for the cloud studies}

LIDARs are well suited and widely used for determining the characteristics of clouds, especially high altitude clouds, because of their high range resolution and high sensitivity to hydrometeors. The sharp enhancement in the Mie backscattered LIDAR signal makes possible the detection and characterization of the clouds (Fernald, 1984). Although one channel LIDAR can define physical boundaries of clouds, polarization diversity gives fundamental principles to distinguish between water and ice phase of the clouds. The LIDAR measurements of scattering ratio and linear depolarization ratio (LDR) provide the cloud parameters and information on the thermodynamic phase of the cloud particles.

\section{LIDAR to determine middle atmospheric temperature}

In the height range, where the contribution from the Mie backscatter is negligible ( $\geq 30 \mathrm{~km})$, the recorded signal is due to the Rayleigh backscatter and its intensity, corrected for the range and atmosphere transmission, is proportional to the molecular number density. Using the number density taken from an appropriate model for a specified height, where the signal-to-noise ratio is fairly high, the constant of proportionality is evaluated and thereby the density profile is derived. Taking the pressure at the top of the height range (say $90 \mathrm{~km}$ ) from the atmospheric model, the pressure profile is computed using the measured density profile, assuming the atmosphere to be in hydrostatic equilibrium. Adopting the perfect gas law, the temperature profile is computed using the derived density and pressure profiles. The analysis closely follows the method described by Hauchecorne and Chanin (1980).

\section{LIDAR to determine the wind speed}

Doppler LIDARs make use of the small change in the operating frequency of the LIDAR due to motion of the scatterers to measure their velocity. Using the technique called heterodyning, the returned backscattered signal is used with another laser beam so that they interfere, yielding a more easily measurable signal at radio wave frequency. The frequency of the radio wave will be equal to the difference between the frequencies of the transmitted and the received signals. The application of Doppler LIDAR in atmospheric remote sensing is to measure wind velocity, i.e., wind speed and direction in addition to other parameters.

\section{LIDAR for the measurements of vertical profile of ozone}

The DIAL technique has been used to provide vertical profiles of the ozone number density from ground to $40-50 \mathrm{~km}$ height level. The basic principle of the DIAL technique is described in earlier section (section 2.3.1). In this technique, the laser transmitter emits signals at two close wavelengths, $\lambda_{\text {on }}$ and $\lambda_{\text {off }}$ corresponding to a peak and trough, respectively in the absorption spectrum of the species of interest. The ratio of the two received signals due to backscattering corresponds to the absorption produced by the 
species $\left(\mathrm{O}_{3}\right)$ in the range cell defined by the laser pulse duration and receiver gate. The amount of absorption is directly related to the concentration of the constituent.

\section{LIDAR for lower atmospheric temperature and minor constituents}

Raman LIDAR is useful in obtaining molecular nitrogen concentration from low altitudes (below $30 \mathrm{~km}$ ) where Rayleigh LIDAR technique is not applicable due to the presence of aerosols. In case of Raman scattered signal the radiation emerging only from the $\mathrm{N}_{2}$ molecules are detected that is proportional to the number density of air molecules. Temperature could be derived from the number density as the case of Rayleigh LIDAR. Raman scattering is also used to detect different molecular species present in the atmosphere.

\section{LIDAR in space}

Ground-based LIDAR provides atmospheric data over a single viewing site, while LIDAR aboard an aircraft can gather data over an area confined to a region. Thus the ground-based and airborne LIDARs provide data over a limited area of a specified region of the earth. Space borne (satellite-based) LIDARs, on the other hand, have the potential for collecting data on a global scale, including remote areas like the open ocean, in a short period of time.

\section{Lidar activities in south africa}

Although ground-based LIDAR systems exist in many developed countries and largely concentrated in northern hemisphere mid- and high latitude, it is still a very novel technique for South Africa and African countries. A recent survey on the available LIDAR system around the world, noticed that there are currently two different LIDARs available in South Africa, located in Pretoria and Durban (see. Figure 2). Both LIDAR systems are similar in operation and different in specifications and the objectives of measurements. The Durban LIDAR is operated at University of KwaZulu-Natal as part of cooperation between the

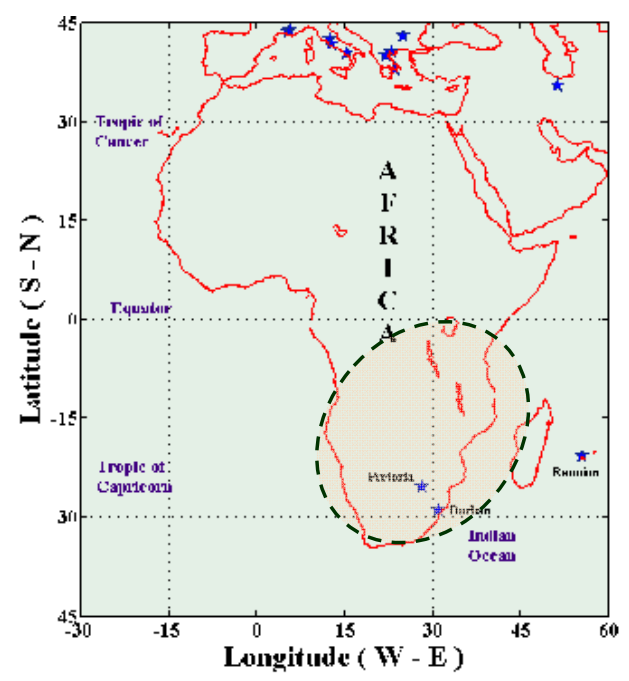

Fig. 2. Geo-graphical position of LIDAR sites in Pretoria and Durban. 
Reunion University and the Service d'Aéronomie (CNRS, IPSL, Paris) for atmosphere research studies, especially to study the upper troposphere and lower stratosphere (UTLS) aerosol structure and middle atmosphere temperature structure and Dynamics. The Council for Scientific and Industrial Research (CSIR) National Laser Centre (NLC) in South Africa has recently designed and developed a mobile LIDAR system to contribute to lower atmospheric research in South Africa and African countries. The CSIR mobile LIDAR acts as an ideal tool to address atmospheric remote sensing measurements from ground to $40 \mathrm{~km}$ and to study the atmosphere aerosol/cloud studies over Southern Hemisphere regions and this will encourage collaboration with other partner's in-terms of space-borne and ground based LIDAR measurements.

\section{CSIR - NLC mobile LIDAR system}

\subsection{System description}

The CSIR NLC mobile LIDAR has been configured into mono-static that maximizes the overlap of the outgoing beam with the receiver field of view. The LIDAR system has been mounted in a mobile platform (van) with a special shock absorber frame. Figure 3 shows a 3-D pictorial representation of the mobile LIDAR with 2-D scanner. In general, any LIDAR systems can be sub-divided into three main sections, a laser transmitter, an optical receiver and a data acquisition system.

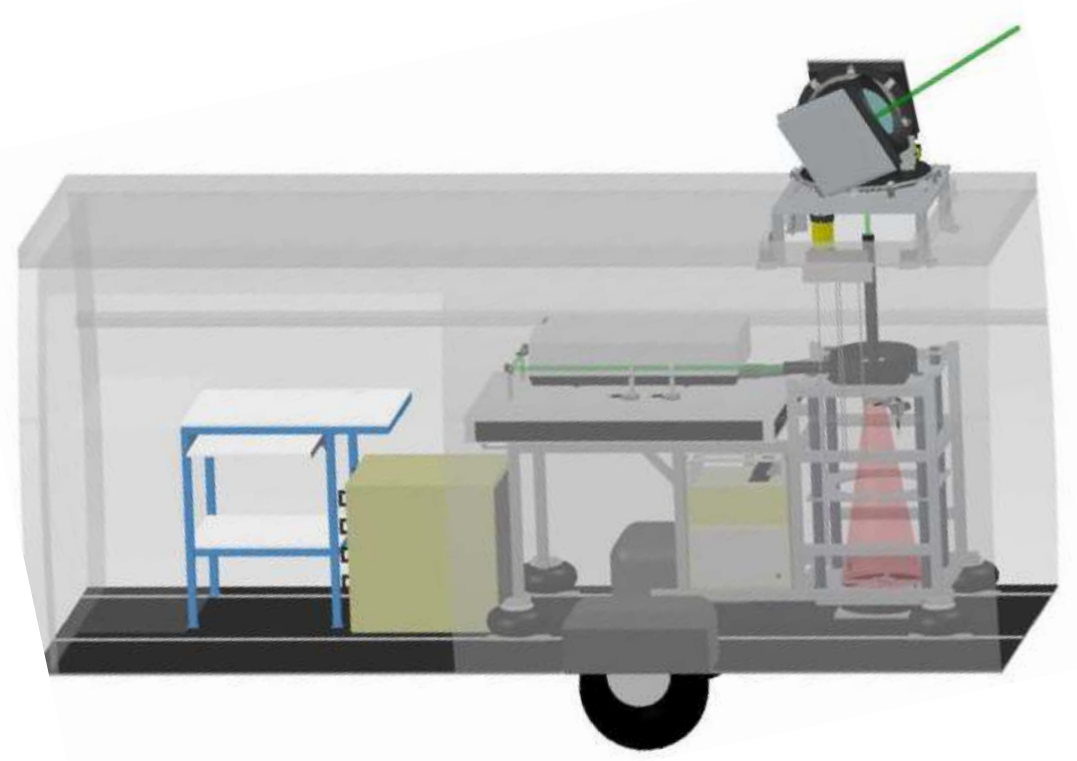

Fig. 3. A 3-D pictorial representation of the CSIR-NLC mobile LIDAR with 2-D scanner 
The important main specifications of the LIDAR system are listed in Table 3.

\begin{tabular}{|c|c|}
\hline Parameters & Specifications \\
\hline \multicolumn{2}{|l|}{ Transmitter } \\
\hline Laser Source & Nd:YAG - Continuum ${ }^{\circledR}$ \\
\hline Operating Wavelength & $532 \mathrm{~nm}$ and $355 \mathrm{~nm}$ \\
\hline Average pulse energy & $120 \mathrm{~mJ}($ at $532 \mathrm{~nm}) 80 \mathrm{~mJ}($ at $355 \mathrm{~nm})$ \\
\hline Beam Expander & $5 x$ \\
\hline Pulse width & $7 \mathrm{~ns}$ \\
\hline Pulse repetition rate & $10 \mathrm{~Hz}$ \\
\hline Beam Divergence & 0.12 mrad after Beam Expander \\
\hline \multicolumn{2}{|l|}{ Receiver } \\
\hline Telescope type & Newtonian \\
\hline Diameter & $404 \mathrm{~mm}$ \\
\hline Field of View & $0.5 \mathrm{mrad}$ \\
\hline PMT & Hamamatsu® R7400-U20 \\
\hline Optical fibre & Multimode, $600 \mu \mathrm{m}$ core \\
\hline Filter FWHM & $0.7 \mathrm{~nm}$ \\
\hline \multicolumn{2}{|c|}{ Signal and Data Processing } \\
\hline Model & Licel® TR15-40 \\
\hline Memory Depth & 4096 \\
\hline Maximum Range & $40.96 \mathrm{~km}$ \\
\hline Spatial Resolution & $10 \mathrm{~m}$ \\
\hline \multicolumn{2}{|l|}{ PC } \\
\hline TR15-40 Interface & Ethernet \\
\hline Processor & Intel ${ }^{\circledR}$ Core2Duo $2.6 \mathrm{GHz}$ \\
\hline Operating system & Windows ${ }^{\circledR}$ XP Pro \\
\hline Software Interface & NI LabVIEW® \\
\hline \multicolumn{2}{|l|}{ Application } \\
\hline Aerosol/Cloud study & $0.5 \mathrm{~km}$ to $40 \mathrm{~km}$ \\
\hline Water Vapour & $0.5 \mathrm{~km}$ to $12 \mathrm{~km}$ (to be done) \\
\hline Temperature & $0.5 \mathrm{~km}$ to $20 \mathrm{~km}$ (to be done) \\
\hline \multicolumn{2}{|c|}{ Scanner resolution (minimum) } \\
\hline X-axis (Horizontal) & $0.002 \mathrm{rad}$ \\
\hline Y-axis (Vertical) & $0.001 \mathrm{rad}$ \\
\hline
\end{tabular}

Table 3. Major specifications of the CSIR-NLC mobile LIDAR system 


\subsubsection{Laser transmission}

The transmitter employs a Q-Switched, flash lamp pumped Nd:YAG (Neodymium (Nd) impurity ion concentration in the Yttrium Aluminum Garnet (YAG)) solid-state pulsed laser (Continuum ${ }^{\circledR}$, PL8010). Nd:YAG lasers operate at a fundamental wavelength of 1064 $\mathrm{nm}$. Second and third harmonic conversions are sometimes required, depending on the application and are accomplished by means of suitable non-linear crystals such as Potassium (K) Di-hydrogen Phosphate (KDP). At present, the second (532 nm) and third $(355 \mathrm{~nm})$ harmonic is utilized and the corresponding laser beam diameter is approximately 8 $\mathrm{mm}$. The laser beam is passed through a beam expander (expansion of 5 times), before being sent into the atmosphere, thereby the beam divergence is reduced by the factor of 5 (i.e, 0.6 mrad to $0.12 \mathrm{mrad}$ ). The resultant expanded beam has a diameter of $40 \mathrm{~mm}$ and is then reflected upward using a flat, 45 degree turning mirror. The entire transmission setup is mounted on an optical breadboard. The power supply unit controls and monitors the operation of the laser. It allows the user to setup the laser's flash lamp voltage, Q-Switch delay and the laser repetition rate. It also monitors system diagnostics such as the flow and temperature interlocks. The power supply also incorporates a water to water heat exchanger which regulates the temperature and quality of water used to cool the flash lamps and laser rods. The inbuilt laser Control Unit (CU601) provides cooling group interlocks, which sense water temperature, water level and water flow. A cooling group interlock violation halts the laser operation and reports the interlock violation to the remote box. At present, the laser is being utilized at the pulse repetition rate of $10 \mathrm{~Hz}$.

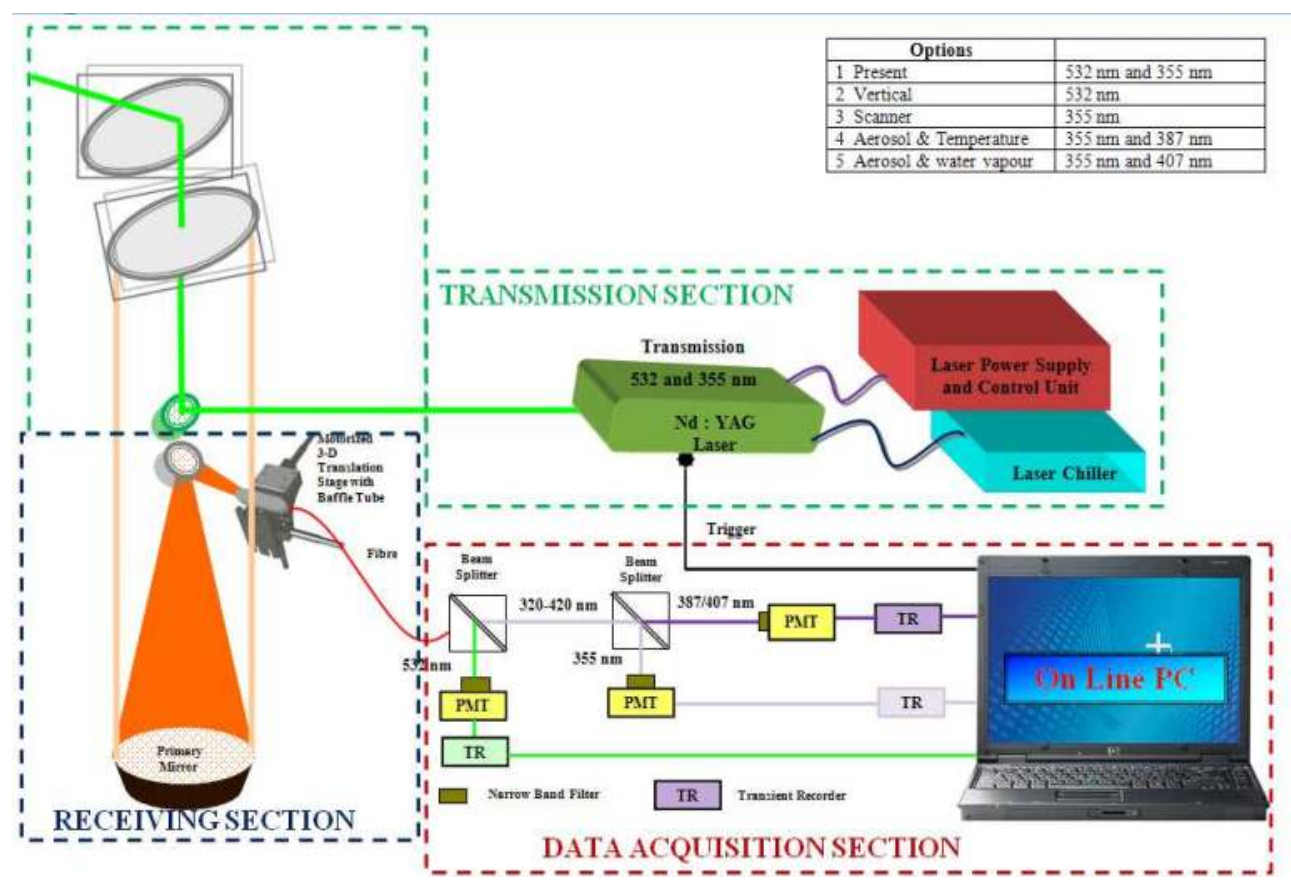

Fig. 4. Block diagram of CSIR-NLC mobile LIDAR illustrating different components. 


\subsubsection{Receiver section}

The receiver system employs a Newtonian telescope configuration with a $404 \mathrm{~mm}$ primary mirror. The backscattered signal is first collected and focussed by the primary mirror of the telescope. The primary reflecting mirror has a $2.4 \mathrm{~m}$ radius of curvature and is coated with an enhanced aluminium substrate. The signal is then focused toward to a secondary 45 degree plane mirror and coupled into an optical fibre. One end of the fibre is connected to an optical baffle which receives the return signal from the telescope. The other end is connected to an optical tube with collimation optics and the PMT. We have also employed a motorized 3-Dimensional translation stage in order to accurately align the fibre using PC control.

\subsubsection{Data acquisition}

PMT is used to convert the optical backscatter signal to an electronic signal. The PMT is installed in an optical tube and is preceded by a collimation lens and narrow band pass filter. The PMT used is a Hamamatsu R7400-U20. It is a subminiature PMT which operates in the UV to NIR wavelength range ( $300 \mathrm{~nm}-900 \mathrm{~nm})$ and has a fast rise time response of $0.78 \mathrm{~ns}$. It is specially selected for minimal noise with an anode dark current.

Data acquisition is performed by a Licel transient recorder (TR). The system is favored by its dual capability of simultaneous acquiring analog and photon count signal, which makes it highly suited to LIDAR applications by providing a higher dynamic range. The TR15-40 is the model that was procured. It is capable of $15 \mathrm{MHz}$ sampling and has a memory depth of 4096 bins. The photon count channel uses a high pass filter to select the high frequency component $(>10 \mathrm{MHz})$ of the amplified PMT signal. The filtered component is then passed through a fast discriminator $(250 \mathrm{MHz})$ and counter enabling the detection of single photons. The Licel system together with a LabVIEW software interface allows the user to acquire signals without any immediate programming. As mentioned earlier, the Licel data acquisition system incorporates electronics which is capable of simultaneous acquisitions of Analog Data (AD) and Photon Count (PC) data with a range resolution of $10 \mathrm{~m}$. The combination of $\mathrm{PC}$ and $\mathrm{AD}$ electronics greatly extends the dynamic range of the detection channel allowing the reduction or removal of neutral density filters, which in turn greatly improves the Signal-to-Noise Ratio (SNR). The measurements are usually done at night to minimize back-ground noise.

\subsection{Illustration}

In general, the laser beam is directed vertically upward into the sky as depicted in figure-3. The corresponding day presented a cloudy sky and there was a passage of high-altitude cirrus, which is normally found at upper altitudes from $6 \mathrm{~km}$ to $15 \mathrm{~km}$. Since these clouds are generally optically transparent, depend upon the physical property, laser light is passed/prevented from passing through. The observations were carried out for approximately four and a half hours and the presence of clouds is clearly seen in the heighttime-backscattered signal returns for both the Analog Data (AD) and Photon Count (PC) data which is presented in Figs. 5 and 6 respectively. The figures were obtained after modifying the provided Licel-LABVIEW software, in-house, to display an automatically updated height-time-backscatter colour map in real time. The advantage of such a program 


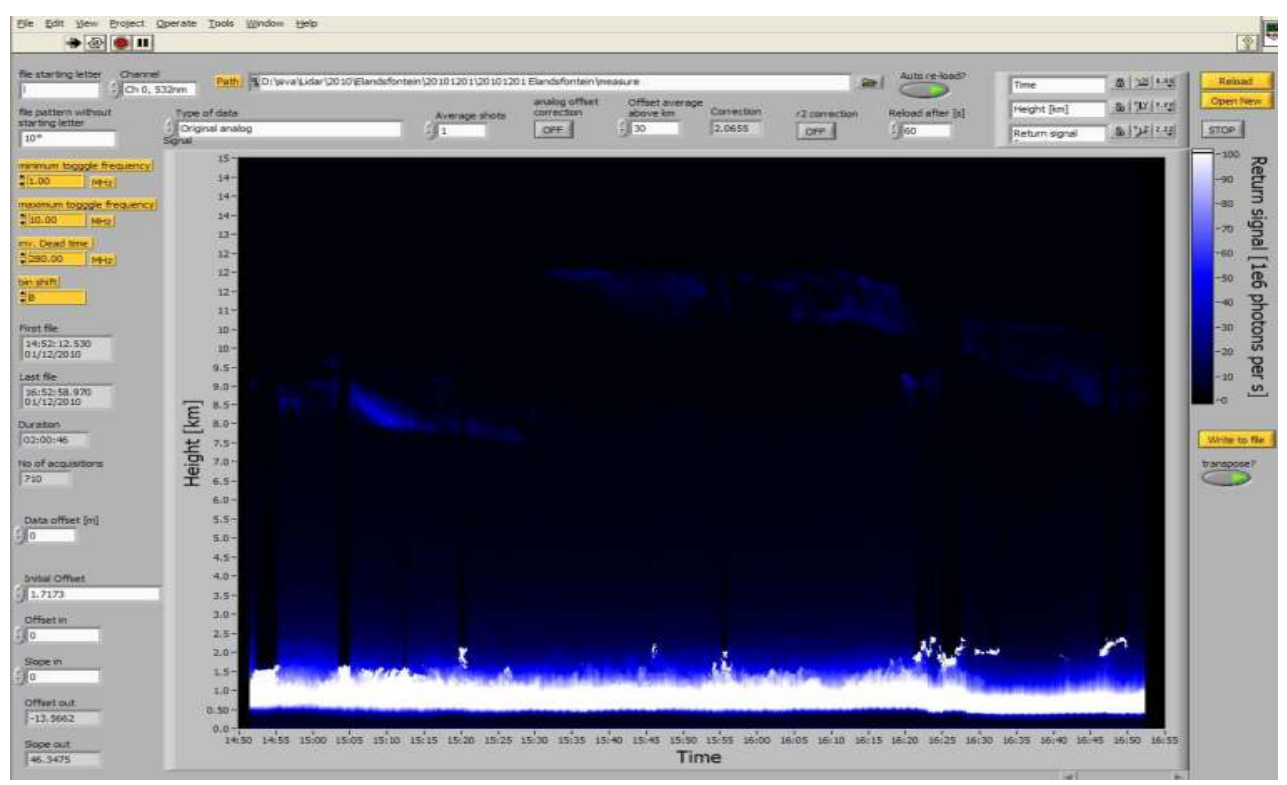

Fig. 5. Original analog signal measured on 01 December 2010

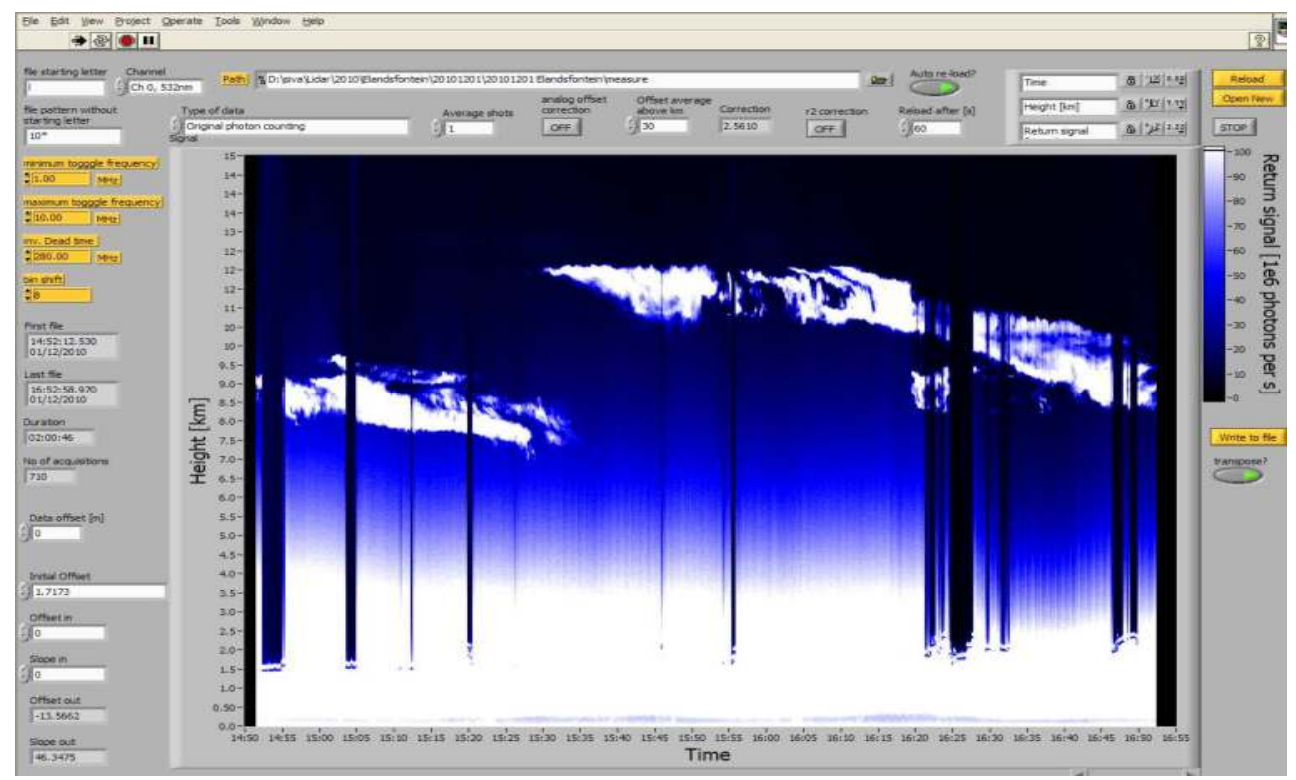

Fig. 6. Same as fig. 5 but represents the original photon count signal

is that it allows the user to infer the data simultaneously while the LIDAR system is in operational. The display can be easily visualized and the available settings enable either the $\mathrm{AD}$ or the PC data to be displayed, as required. 
The simultaneous $\mathrm{AD}$ and $\mathrm{PC}$ acquisitions have been post processed to merge or 'glue' the datasets into a single return signal. The combined AD and PC signals allow us to use the analog data in the high signal to noise ratio (SNR) regions and the PC data in the low SNR regions. Since the output from the $\mathrm{AD}$ converter is voltage $(\mathrm{V})$ and the output from the photon counter is counts or count rates $(\mathrm{MHz})$ a conversion factor between those outputs needs to be determined in order to convert the analog data to "virtual" count rate units. First the PC data is corrected for pulse pileup using a non-paralyzable assumption (dead-time correction). The dead time corrected PC data is then determined based on the linear relationship with Analog Signal, i.e., $\mathrm{PC}=a * \mathrm{AD}+b$, over a range where the $\mathrm{PC}$ data responds linearly to the $\mathrm{AD}$ and where the $\mathrm{AD}$ is significantly above the inherent noise floor. The linear regression has been applied to determine the gain and offset coefficients (gluing coefficients), $a$ and $b$. Thereafter, the coefficients are used to convert the entire AD profile to a "virtual/scaled" photon count rate. This is referred to as the scaled analog signal. i.e., the term, " $a{ }^{*} \mathrm{AD}^{\prime}$ (see. Figure 7) and the term ' $b$ ' stands for the bin shift (offset). Commonly, the typical range is determined from the data above the threshold signal and where the PC data (see. Figure 8) is between $0.5 \mathrm{MHz}$ and $10 \mathrm{MHz}$. The combined or glued signal then uses the dead-time corrected PC data for count rates below some threshold (typically $10 \mathrm{MHz}$ ) and the converted/scaled AD data above this point. Figure 9 displays the glued data for the above presented case (see Figure 7 and 8). Here, the gluing is performed after obtaining the dead time corrected photon count (dead time is $3.6 \mathrm{n} \mathrm{sec}$ ) and also adjusting a minute bin shift between the AD and PC. The bin shift is basically a delay measured in bins (corresponding to $10 \mathrm{~m}$ per bin) which occurs due the detection electronics. Filters in the pre-amplifier electronics results in a delay of the AD signal with respect to the PC signal. The analog to digital conversion process also may also cause any further delay.

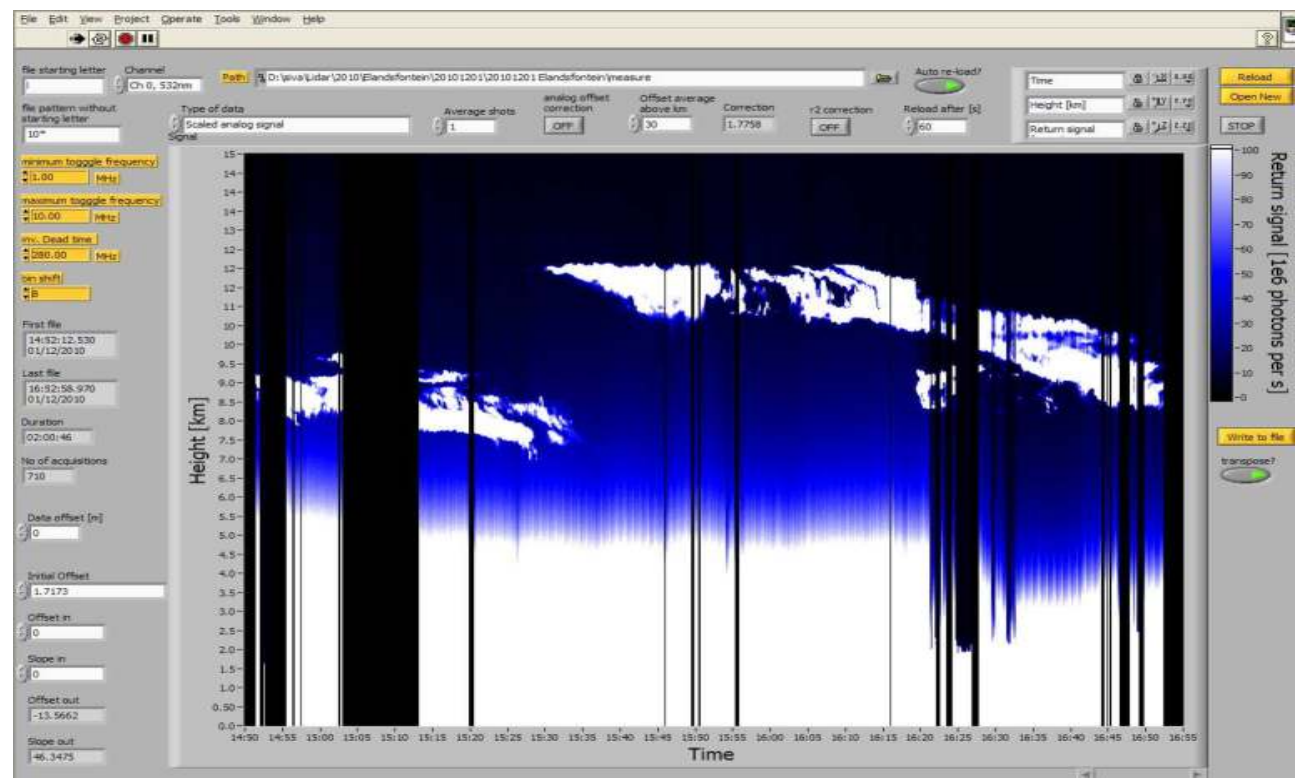

Fig. 7. Same as fig. 5 but represents the scaled analog signal 


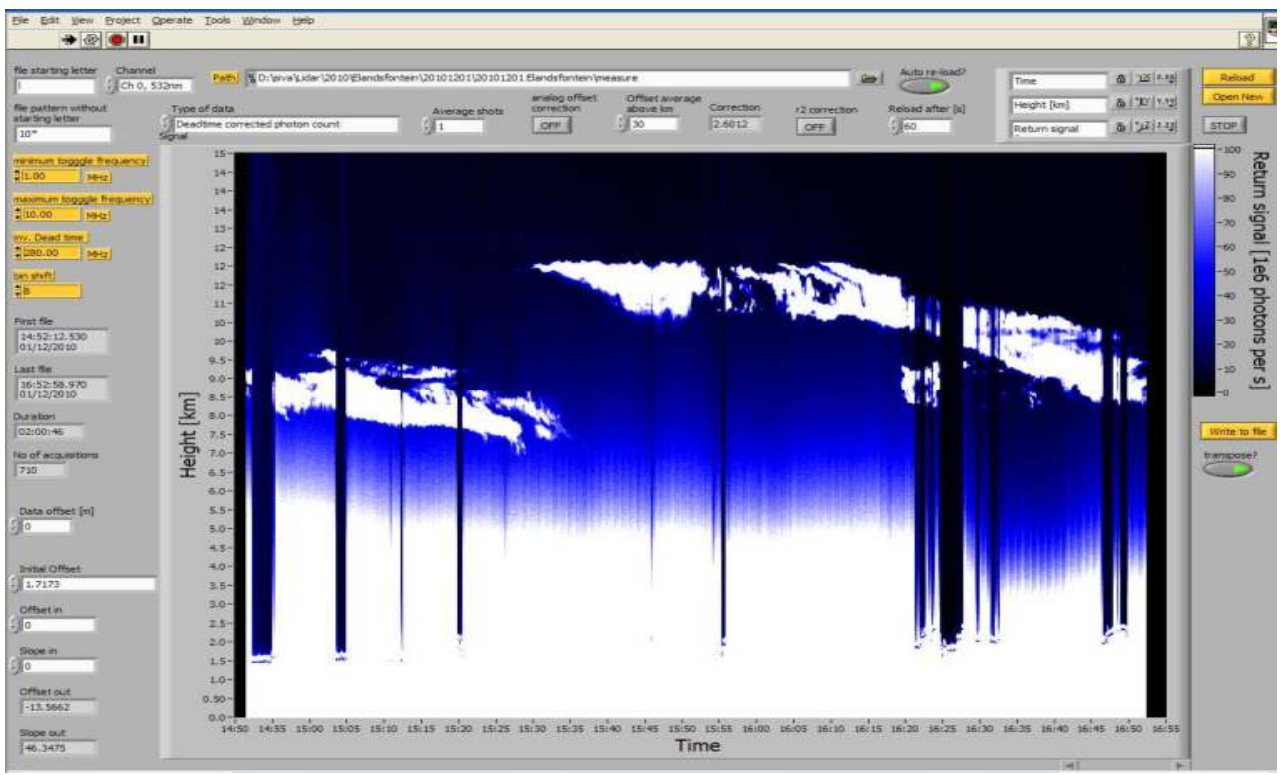

Fig. 8. Same as fig. 5 but represents the deadtime corrected photon count signal

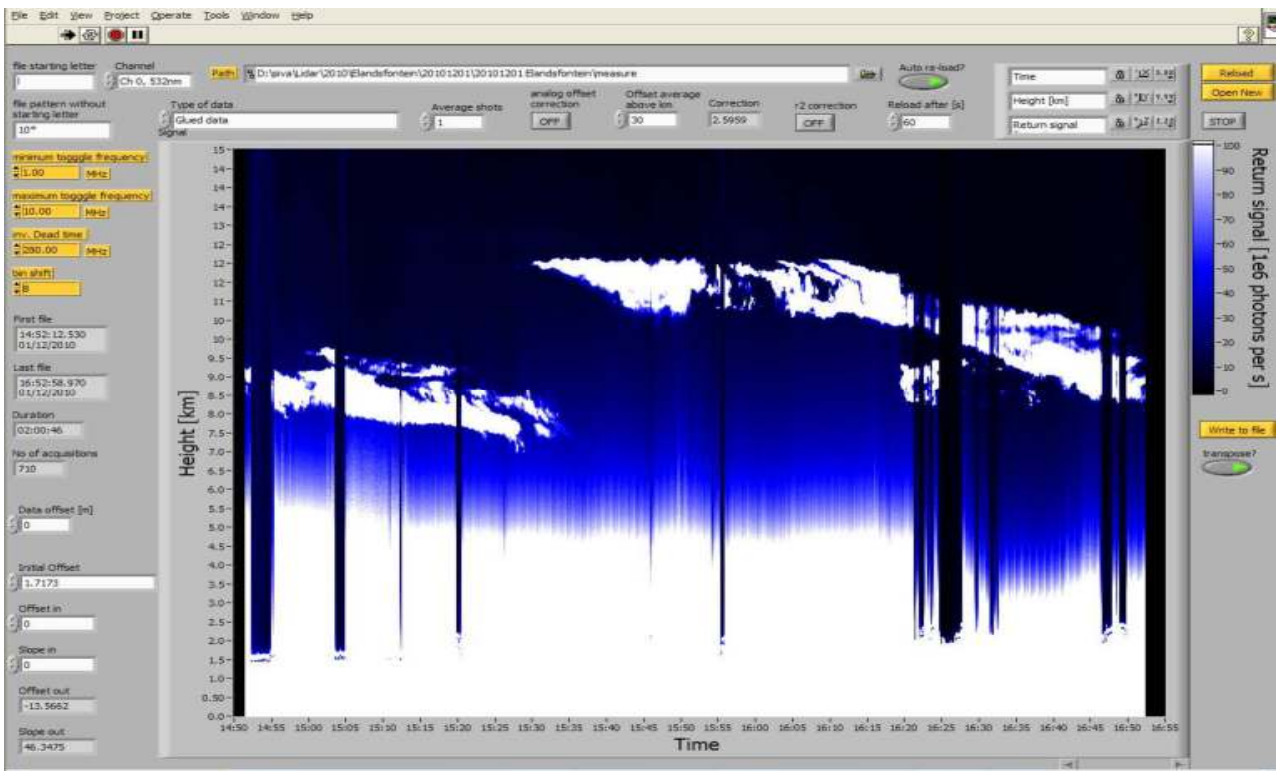

Fig. 9. Same as fig. 5 but represents the glued photon count signal

To address the dynamic range of the instrument, the range corrected glued signal (i.e., signal multiplied by $\mathrm{R}^{2}$ ) is presented in figure 10. i.e., the figures represented here are the raw data multiplied by the square of the altitude, commonly referred as range corrected 


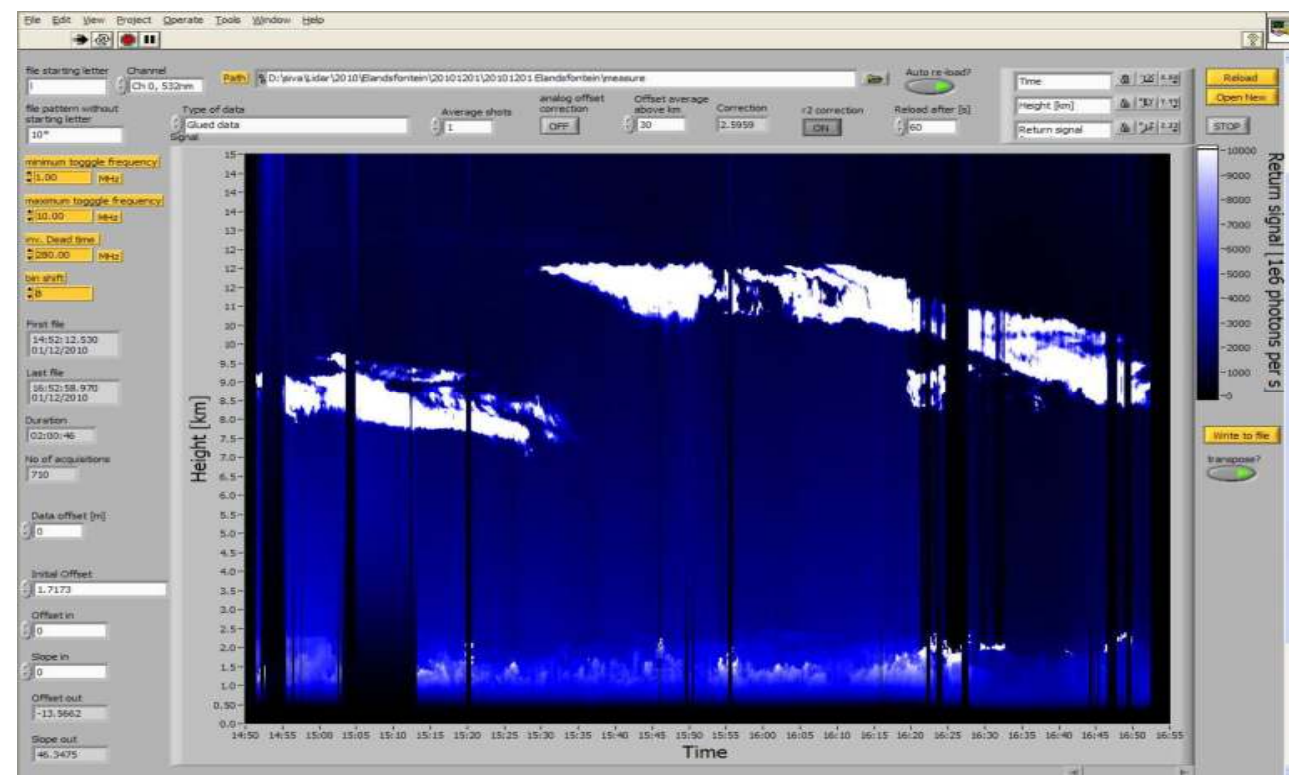

Fig. 10. Same as fig. 9 but represents the Range Corrected glued photon count signal

signal. The range corrected signal provides an equilibrium condition to the LIDAR transmitted and received backscatter signal (see. Equation 1).

The figures clearly distinguish the cloud observation from normal scattering from background particulate matter. Sharp enhancements are observed around $7.5 \mathrm{~km}$ and above $(\sim 12 \mathrm{~km})$ indicating the presence of cloud. Such type of cloud otherwise termed as CIRRUS. The advantage of using LIDAR, is to observe the cloud thickness in addition to the cloud height. This is one of the important advantages of LIDAR measurements, in comparison with any other remote sensing measurement techniques. The advantage of having high resolution data $(10 \mathrm{~m})$ further address the accurate detection of cloud height and thickness, which is important for studying the cloud morphology. Apart from it, the above measurements illustrate the dynamic range of the LIDAR signal upto $35 \mathrm{~km}$ (though the figure is presented here upto $15 \mathrm{~km}$ ). During the day-time measurements, to avoid the background light signal, neutral density (ND) filters are employed which protect further the PMT saturation and to investigate the maximum return signal strength.

The parameter, SNR judge always any instrument capability. Here, we have determined for the mobile LIDAR based on transmitting and receiving signal with and without emitting the LASER beam. The results are obtained by operating the LIDAR on a clear sky with the laser is being ON (Signal) and OFF (Noise) for an about twelve minutes in each cases (see Figure 11a). Figure 11(a) illustrates the temporal evolutions of LIDAR signal returns when the laser is ON and OFF. While the laser was on (first twelve minutes), a large photon count signal was obtained and when the laser was switched off (next twelve minutes), random noise photons are observed due to the background scattering from the atmosphere.

The above individual observational data are then averaged temporally and presented as a height profile of photon count in Figure 11b. Figure represents both the signal (blue) and 


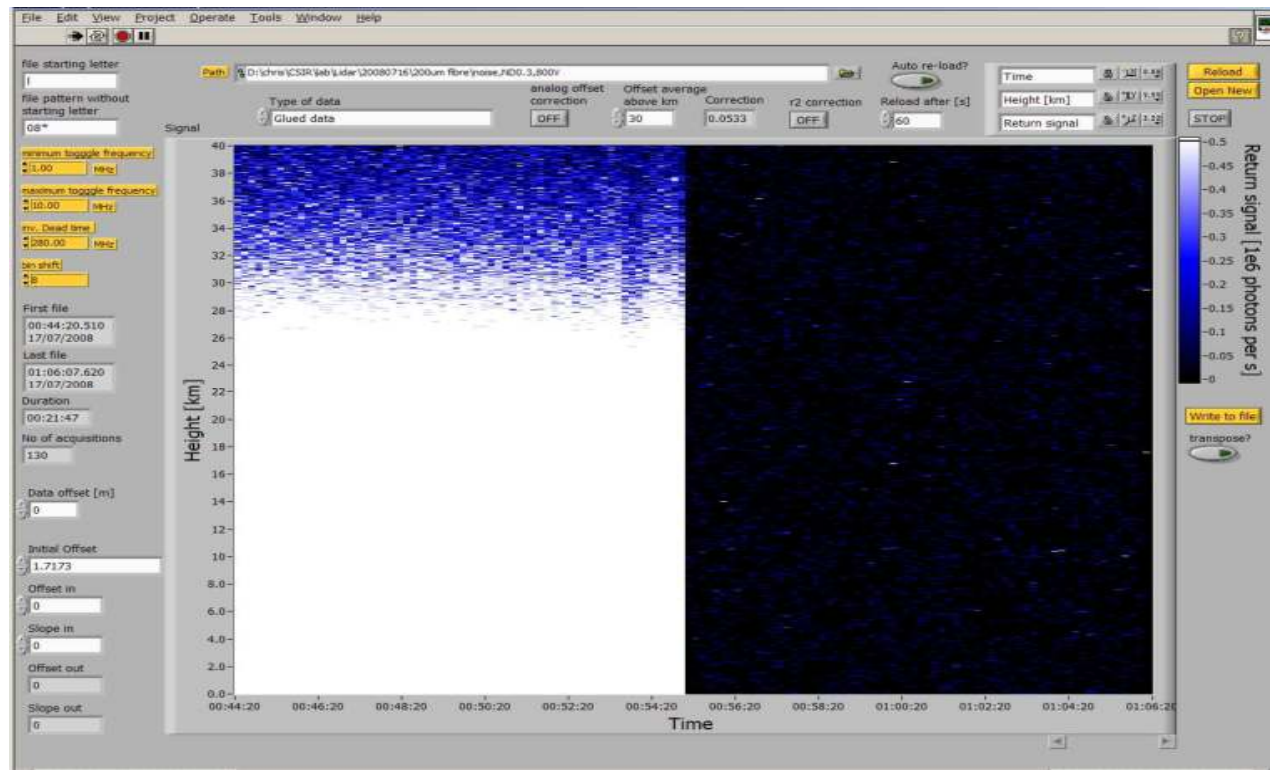

Fig. 11a. Temporal evolution of the return signal while LASER is ON and OFF mode.

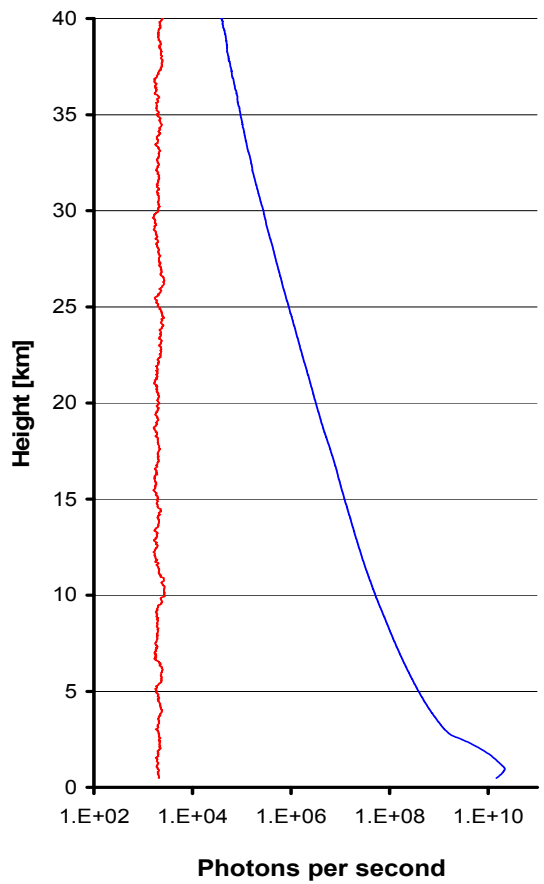

Fig. 11b. Height profile of averaged photon count for the above presented temporal evolution in fig. 11a. 
noise (red) profiles. It is clear from the figure that the signal strength for the height region up to $40 \mathrm{~km}$ and shows more than 2 orders apart from the noise level. From the above results, one can conclude that the LIDAR provides reasonable measurements for the height region up to $40 \mathrm{~km}$ and that the signal to noise ratio is highly apart by an order of two. Further, more integration of signal may also address improvements in the SNR and the dynamic range of the instruments.

\subsection{Scientific results}

\subsubsection{LIDAR extinction co-efficient}

The altitude profiles of aerosol extinction $(\alpha)$ or backscatter coefficient $(\beta)$ from a backscattered LIDAR signal require the solution from the LIDAR equation (see. Equation 1 ). As described in the LIDAR equation, the $\beta(\mathrm{z})=\left[\beta_{\mathrm{a}}(\mathrm{z})+\beta_{\mathrm{m}}(\mathrm{z})\right]$, and $\alpha(\mathrm{z})=\left[\alpha_{\mathrm{a}}(\mathrm{z})+\alpha_{\mathrm{m}}(\mathrm{z})\right]$, where, $\alpha_{a}$ and $\beta_{a}$ are the volume extinction and backscatter coefficients of the aerosols and $\alpha_{\mathrm{m}}$ and $\beta_{\mathrm{m}}$ are the volume extinction and backscatter coefficients of the air molecules. The values of $\alpha_{\mathrm{m}}$ and $\beta_{\mathrm{m}}$ are calculated from the meteorological data or from a standard atmosphere model. Determinations of $\alpha_{a}$ and $\beta_{a}$ require an inversion of the LIDAR equation. The inversion is not a straightforward process since it involves two unknowns. In this regard, a definitive relationship between the above two unknowns should be assumed. The molecular contributions to backscattering and extinction have been estimated using a reference model atmosphere (MSISE-90). This is accomplished by the normalization of the photon count with molecular density at a specified height (vary from a day to day) taken from a model (MSISE-90) and then applying the extinction correction to the backscattering co-efficient profile using iterative analysis of the LIDAR inversion equation. The estimation of aerosol backscatter co-efficient applies the downward progression from the reference altitude of $\sim 40 \mathrm{~km}$ where the aerosol concentration is said to be negligible. The backscattering co-efficient profiles as computed above are also employed for the purpose of studying the cloud characteristics. For studying the aerosol concentrations, however, extinction profiles are computed by following the LIDAR inversion method as described by Klett, (1985).

The LIDAR inversion technique was applied to the backscattered LIDAR signal for a two continuous day measurements $30^{\text {th }}$ and $31^{\text {st }}$ August 2010, to determine the aerosol backscatter and extinction coefficient. Figure 12 shows the 10 minutes averaged height profile of the aerosol extinction coefficient retrieved from LIDAR signal returned on the 30 th and 31st August 2010. Different height profiles for measurements on the same day are observed. It shows that the aerosols loading were not found to be stable over the measurement site. This is due to the change in the aerosol loading resulting from the change in humidity, temperature, etc. Furthermore, the differences between measurements on different day are observed. This might be due to the variations in day's background conditions, temperature, humidity, wind, cloud, solar radiation, etc.

\subsubsection{Detection of cloud}

Figure 13 shows an example of detection of cloud by LIDAR for the night of 23 February 2008. The laser was directed vertically upward into the sky and the corresponding night was a cloudy sky and there was a passage of cumulous clouds which is normally found at lower 


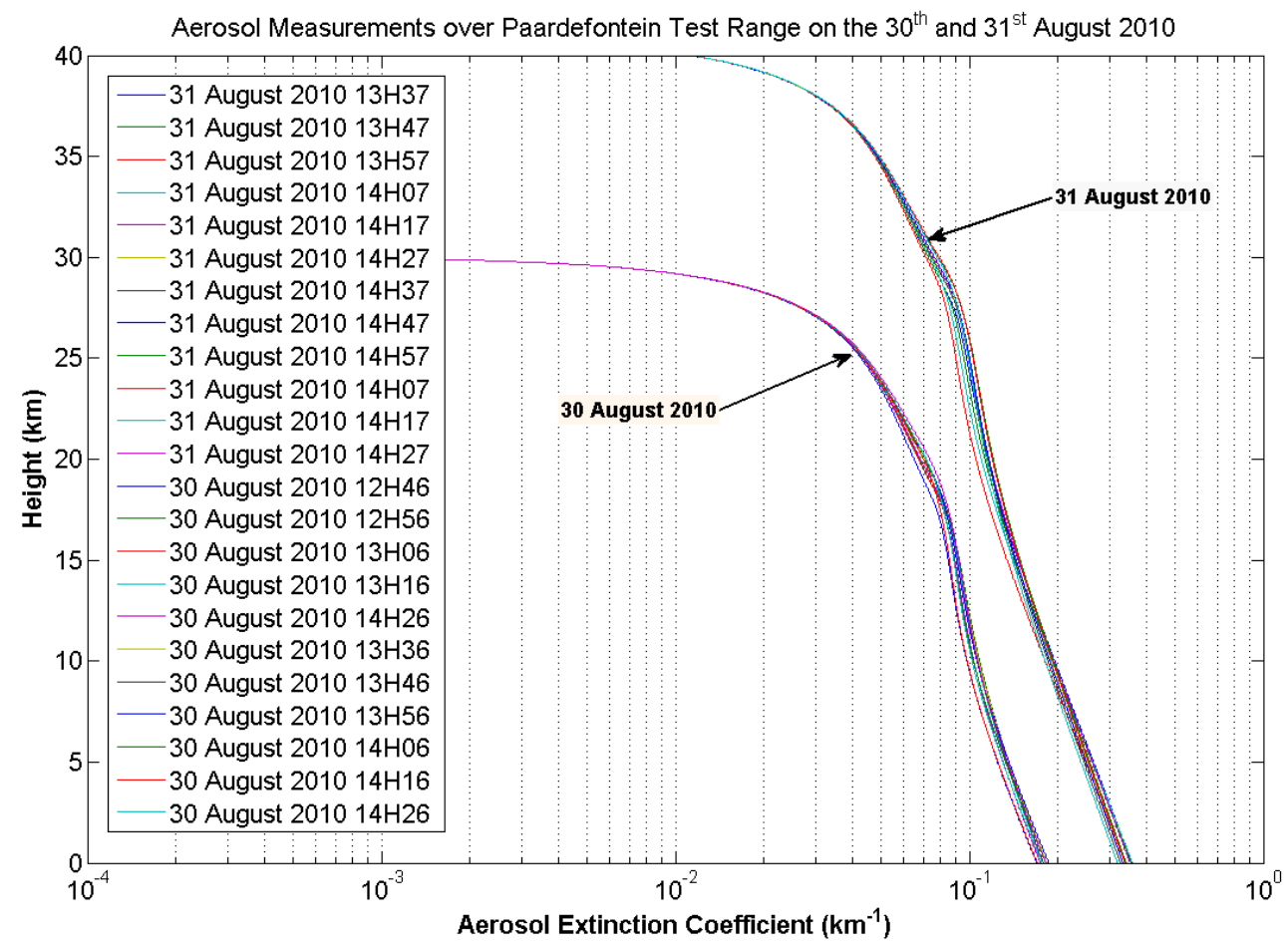

Fig. 12. Height profile of aerosol extinction coefficient retrieved from LIDAR returned signal for the 30th and 31 st August 2010.

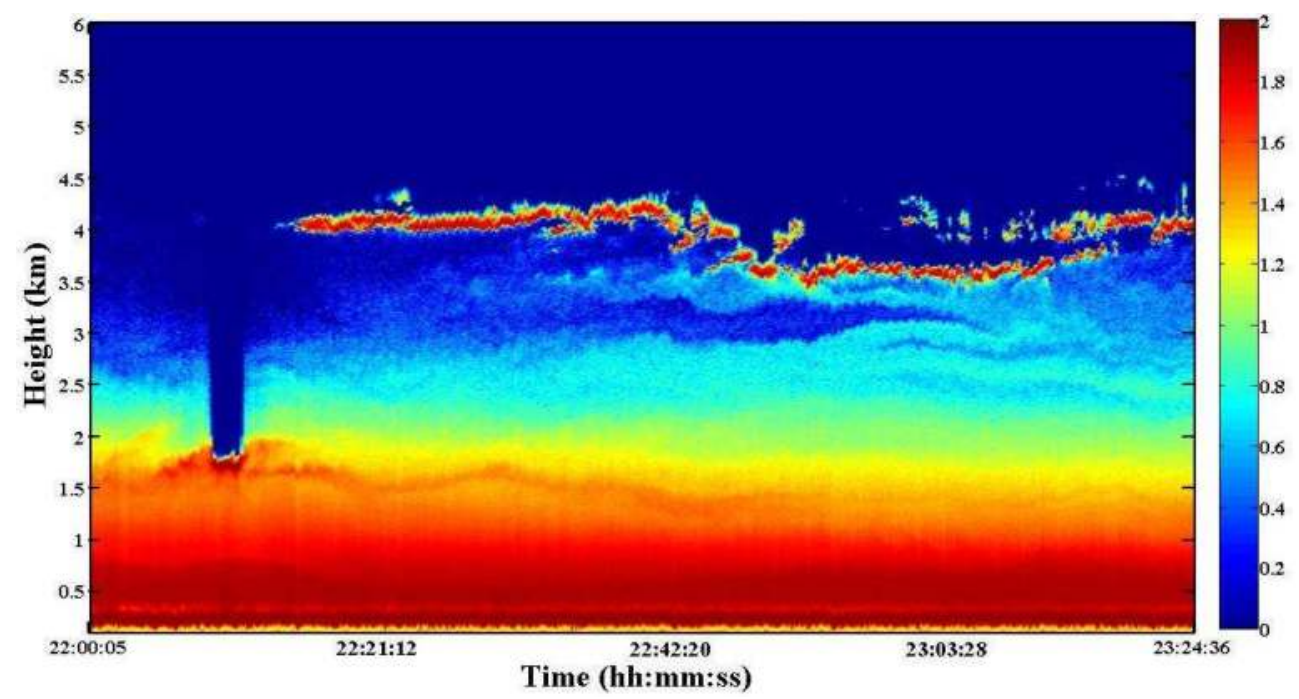

Fig. 13. Height-time-colour map of LIDAR signal returns for 23 February 2008. 
height region from $3 \mathrm{~km}$ to $5 \mathrm{~km}$. Since, these clouds are generally optically dense which prevents light to pass through. The present observations were carried out for more than two hours and the presence of clouds is clearly seen in the height-time-backscattered signal returns. Figure clearly distinguishes the cloud observation from normal scattering from background particulate matter. It shows the sharp enhancement in backscatter signal during the presence of cloud around $3.8 \mathrm{~km}$ and slowly has moved down to $3.5 \mathrm{~km}$. The figure also demonstrates the capability of LIDAR to observe the cloud thickness (less than around 300 $\mathrm{m})$ which is a unique feature of LIDAR in comparison to the satellite detection. The measured high resolution data is also important when studying cloud physics/characteristics. Otherwise, the lower height regions indicate high intensity signal returns which is due to the presence fog or aerosols.

\subsubsection{Boundary layer detection}

The atmospheric Boundary Layer (BL) is a part of the lower troposphere where most living beings and natural/human activities occur. It varies with space and time, and changes with height mostly during the day due to variations in solar-radiation (by several kilometers) and is quite stable over night. It is well known that the aerosol content or particulate matter in the lower atmosphere fluctuates under different background conditions (e.g., temperature, humidity and solar radiation). Such fluctuations in aerosol content, particularly the height of boundary layer, can easily be determined by means of a LIDAR (Light Detection and Ranging) backscatter signal. Based on the LIDAR backscattered signal (or/and range corrected) and by applying different criteria, one would be able to identify the boundary layer height (BLH) and thus the temporal evolution. Here, we show a typical example of deduction of BLH based on two different methods, (a) statistical and (b) slope, i.e.,

a. The statistical method applies range (z) corrected (squared) LIDAR backscattered signal $\left(P_{r}\right)$, i.e., $P_{r}{ }^{*} z^{2}$. The BLH is identified by the height where the maximum standard deviation in the range corrected signal. Here, the mean value is obtained by the integration of consecutive 5 profiles (corresponds to $50 \mathrm{sec}$ ) (Chiang and Nee, 2006).

b. The slope method is based on the LIDAR backscattered signal $\left(P_{r}\right)$ and their gradient $\left(\mathrm{dP}_{\mathrm{r}} / \mathrm{dz}\right)$. The identified minimum value in the slope (between $\mathrm{P}_{\mathrm{r}}$ and $\mathrm{dP}_{\mathrm{r}} / \mathrm{dz}$ ) defines the BLH (Egert, 2008).

Figure 14 shows the temporal ( $2 \mathrm{hrs}$ ) evolution of LIDAR backscattered signal for the day of 27 May 2011. The figure is superimposed by the deducted BLH based on the two methods, statistical (Black circle) and slope (pink star). It is clear from the figure that the BLH varies significantly over time. In general, maximum BLH is found during the noon, as expected during the day that the earth's surface heats up due to solar radiation and this results in various thermodynamic chemical reactions causing turbulence in the PBL. The boundary layer height is therefore expected to vary more during the day and to stabilize after sun-set. The slope method provided a higher value in comparison with the statistical method (based on standard deviation) and the difference is found to be $\sim 1 \mathrm{~km}$. To conclude, deduction of BLH by the statistical method provides better results compared to the slope method.

\subsubsection{Comparison with satellite measurements}

The extinction profile derived from the LIDAR and compared / validated using ground based and satellite borne instruments. Figure 15 presents the height profile of the extinction 


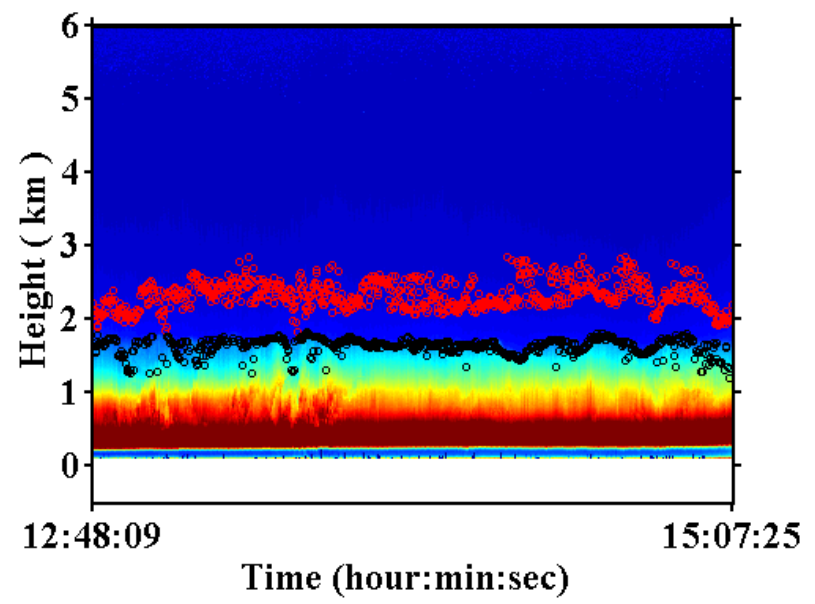

Fig. 14. Height-Time-Color map of LIDAR signal returns (arb.unit) for 27 May 2011. The figure is overlapped by the determined boundary layer height (Black: statistical method based on range corrected signal, Pink: slope method)

coefficient derived from the LIDAR data taken during the nights of 25 February 2008. The profiles are overlapped by the Stratosphere Aerosol Gas Experiment (SAGE-II) extinction data at $525 \mathrm{~nm}$ collected over southern Africa regions (Latitude, $15^{\circ} \mathrm{S}$ to $40^{\circ} \mathrm{S}$ and $10^{\circ} \mathrm{E}$ to $40^{\circ} \mathrm{E}$ and Longitude). The extracted mean aerosol extinction coefficients are from version 6.20 series of $\sim 21$ years (1984-2005). Here, we have used the corresponding monthly-mean extinction profiles (February). We have considered the SAGE-II profile as far as possible above 3-4 km, keeping in mind that the lower height region measurements are inaccurate due to a low signal to noise ratio (SNR) (Formenti et al., 2002). The extinction profiles derived from LIDAR and SAGE-II are in close agreement with respect to trend and magnitude. The LIDAR profile has been terminated above $10 \mathrm{~km}$ due to thick cloud passage. One is able to observe the boundary layer peak at $\sim 2.5 \mathrm{~km}$ which is described earlier, as an important parameter for atmosphere mixing (including pollutants). The presence of a cloud results in a sharp enhancement in the extinction and backscatter co-efficient to a high value making the detection quite unambiguous. A small difference in the observed magnitude might due to employed different techniques between LIDAR and satellite, time of observation, mean satellite profile versus a single day LIDAR measurement. The above mentioned height profile of aerosol extinction coefficients obtained using the LIDAR and SAGE-II satellite data are integrated appropriately to obtain the aerosol optical depth (AOD). Generally, we considered the LIDAR profile for the lower height region with respect to the SNR and at higher altitudes from the SAGE-II data. We found the value for February months is around $\sim 0.264$ which is in good agreement with AOD measured by the photometer over Johannesburg $(0.2966 \pm 0.06668)$. 


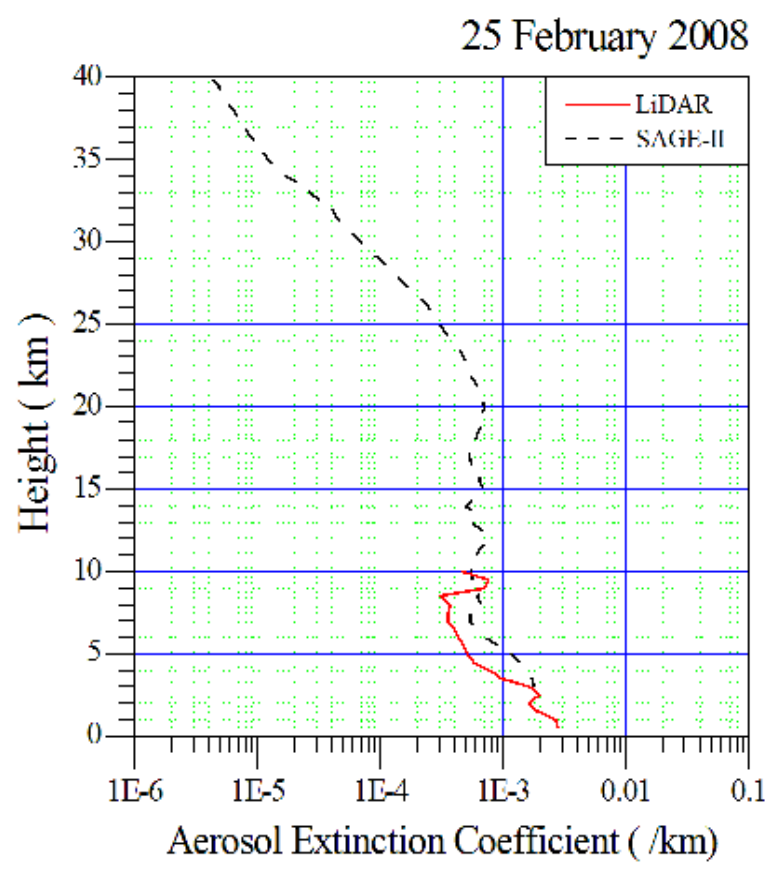

Fig. 15. Height profile of aerosol extinction coefficient derived from LIDAR for the night of 25 February 2008, superimposed by February monthly mean profile of SAGE-II.

\subsection{Future perspectives}

Based on our knowledge, there are no multi-channel LIDAR systems employed for atmosphere research in South Africa and African countries. Our goal is to achieve a multi channel LIDAR system to address aerosol/cloud, water vapour, lower atmosphere temperature and ozone measurements. LIDAR studies on particulate matter $(0.5$ and 0.3 microns) elucidate their distribution and concentration in the atmosphere. Particulate matter plays a key role in atmospheric physical and chemical processes from local to global scale. The complexity of these processes have been largely reviewed in literature and LIDAR measurements have mostly contributed to better understanding the role of atmosphere dynamics and particle microphysics. By making observations on a pre-determined spatial scale (from sites to regions) may plausible to calculate atmospheric mass transport and through trajectory analysis to back-track the location of plume sources, e.g. biomass burning. The atmospheric backscatter measurements of aerosols can be used to identify the stratification of pollutants and will enable the classification of the source regions, such as industrial, biological and anthropogenic sources. Later, the plan is to upgrade the system to measure water vapour concentrations in the atmosphere and its localized variations in the lower troposphere. Water-vapour effects global climate change and global warming both directly (water is a primary green-house gas) and through its impact on ecosystems where vegetation sensitivity plays an important feedback role. 
Further the ongoing plan is to employ a 2-D scanner into the present LIDAR system (see. Figure 2) will be implemented in near future using a cable/pulley system and an electric winch to lift and lower the scanner. The integration of the scanner assists us in terms of

- $\quad$ X-Y dimensional mapping of the atmosphere (horizontal or vertical cross-section)

- Focusing the target (industrial smoke or cloud of pollutants)

- $\quad$ To study the plume (say smoke, biomass burning and etc), Haze and Aerosol/pollutant dispersion.

Successful implementation of scanner will contribute to LIDAR technology worldwide as, with few exceptions, $X-Y$ dimensional mapping of the atmosphere has not been fully explored. The plan is to include online control of the scanner incorporation of the position of the axes into the present data-acquisition system. The attempt will be done to modify the present data-acquisition software to capture the $X-Y$ cross-sectional display during real time measurements.

\section{Acknowledgments}

We are thankful to the different South Africa funding agencies addition to the Council for Scientific and Industrial Research-National Laser Centre (CSIR-NLC), Department of Science and Technology (DST), National Research Foundation (NRF) (Grant no: 65086 and 68668), Southern Educational Research Alliance (SERA), African Laser Centre (ALC), Centre National de la Recherché Scientifique (CNRS) (France) and French Embassy in South Africa (France).

\section{References}

Chiang, C.W. \& Nee, J.B. (2006). Boundary layer height by LIDAR aerosol measurements at Chung-Li $\left(25^{\circ} \mathrm{N}, 121^{\circ} \mathrm{E}\right)$, Proceeding of $23^{\text {rd }}$ International Laser RADAR Conference, $5 \mathrm{O}-$ 6.

Egert, S. \& Peri, D. (2008). Automatic retrieval of the atmospheric boundary layer height, Proceeding of 24 International Laser RADAR Conference, 320-323.

Fernald, F. G. (1984). Analysis of atmospheric lidar observations - some comments, Applied Optics, 23, 652-53.

Fiocco, G. \& Smullin, L.D. (1963). Detection of scattering layers in the upper atmosphere (60人̂-140 km) by Optical RADAR, Nature, 199, 1275 - 1276.

Fiocco, G. (1984). Lidar systems for aerosol studies, An outline, MAP Handbook, Vol. 13 (ed. R.A. Vincent), pp. 56-58.

Formenti, P; Winkler, H., Fourie, P, Piketh, S., Makgopa, B., Helas, G. \& Andreae, M.O. (2002). Aeorosol optical depth over remote semi arid region of South Africa from spectral measurements of the daytime solar extinction and nighttime stellar extinction. Atmospheric Research, 62, 11-32.

Hauchecorne, A. \& Chanin, M. L. (1980). Density and Temperature Profiles Obtained by Lidar Between 35 and 70 km, Geophys. Res. Lett. 7, 565-568.

Klett J.D. (1981). Stable analytical Inversion solution for processing LIDAR returns. Appl. Opt. 20, 211.

Klett, J.D. (1985). LIDAR inversion with variable backscatter to extinction ratios. Appl. Opt, 24, 1638-1645. 
Ligda, M.G.H.(1963). Proceedings of the first conference on laser technology, U.S. Navy, ONR, 63-72. 
REMOTE SENSING

ADVANCED TICHNIQUES AND PLATFORMS

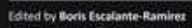

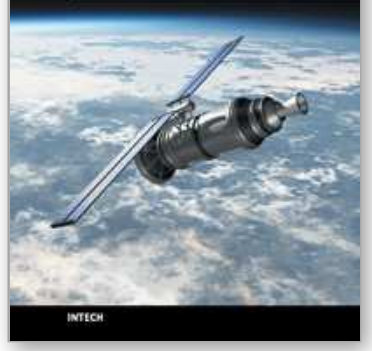

\section{Remote Sensing - Advanced Techniques and Platforms}

Edited by Dr. Boris Escalante

ISBN 978-953-51-0652-4

Hard cover, 462 pages

Publisher InTech

Published online 13, June, 2012

Published in print edition June, 2012

This dual conception of remote sensing brought us to the idea of preparing two different books; in addition to the first book which displays recent advances in remote sensing applications, this book is devoted to new techniques for data processing, sensors and platforms. We do not intend this book to cover all aspects of remote sensing techniques and platforms, since it would be an impossible task for a single volume. Instead, we have collected a number of high-quality, original and representative contributions in those areas.

\section{How to reference}

In order to correctly reference this scholarly work, feel free to copy and paste the following:

Sivakumar Venkataraman (2012). CSIR - NLC Mobile LIDAR for Atmospheric Remote Sensing, Remote Sensing - Advanced Techniques and Platforms, Dr. Boris Escalante (Ed.), ISBN: 978-953-51-0652-4, InTech, Available from: http://www.intechopen.com/books/remote-sensing-advanced-techniques-and-platforms/csirnlc-south-africa-mobile-lidar-for-atmosphere-remote-sensing

\section{INTECH}

open science | open minds

\section{InTech Europe}

University Campus STeP Ri

Slavka Krautzeka 83/A

51000 Rijeka, Croatia

Phone: +385 (51) 770447

Fax: +385 (51) 686166

www.intechopen.com

\section{InTech China}

Unit 405, Office Block, Hotel Equatorial Shanghai

No.65, Yan An Road (West), Shanghai, 200040, China 中国上海市延安西路65号上海国际贵都大饭店办公楼 405 单元

Phone: +86-21-62489820

Fax: $+86-21-62489821$ 
(C) 2012 The Author(s). Licensee IntechOpen. This is an open access article distributed under the terms of the Creative Commons Attribution 3.0 License, which permits unrestricted use, distribution, and reproduction in any medium, provided the original work is properly cited. 